УДК 343.131 .5

DOI $10.18413 / 2075-4566-2019-44-3-467-473$

КРИМИНАЛИСТИЧЕСКАЯ ЗАДАЧА РАССЛЕДОВАНИЯ
- УСТАНОВЛЕНИЕ ПРИЧИН И УСЛОВИЙ,
СПОСОБСТВУЮЩИХ СОВЕРШЕНИЮ ПРЕСТУПЛЕНИЯ

\title{
FORENSIC INVESTIGATION INTO THE CAUSES OF AND CONDITIONS CONDUCIVE TO COMMITTING A CRIME
}

\author{
М.Е. Игнатьев \\ M.E. Ignatiev \\ Московский государственный университет имени М.В. Ломоносова, \\ 119991, ГСП-1, Москва, Ленинские горы, 1, строение 13 \\ Lomonosov Moscow state University Department of criminalistics, \\ 1, building 13 Leninskie Gory, Moscow, GSP-1, 119991, Russia \\ e-mail: 89166810785@mail.ru
}

\begin{abstract}
Аннотация
Дана краткая историческая справка возникновения идеи профилактики преступлений в правовой науке, а также рассмотрены основы исследования данного вопроса в аспекте предмета криминалистики известными отечественными учеными. Приводятся актуальные для современной криминалистики аспекты профилактической деятельности следователя в процессе расследования преступлений на основе установления их причин и условий. Объясняется двухвекторное развитие современной криминалистической профилактики на основе деятельности следователя по предупреждению преступлений, осуществляемой как в процессуальной, так и в не процессуальной форме, а также деятельности эксперта, выявляющего при производстве экспертных исследований обстоятельства, способствовавшие совершению преступления.
\end{abstract}

\begin{abstract}
In this publication, the author considers topical issues related to the problems of establishing the causes and conditions conducive to the Commission of crimes, including those related to the purposes of forensic prevention. At the beginning of the publication provides a brief historical background of the emergence of this issue in legal science, as well as the basis of its research in the aspect of the subject of criminology by well-known domestic scientists. The aspects of preventive activity of the investigator in the course of investigation of crimes because of establishment of their reasons and conditions are given actual for modern criminalistics. Two-vector development of modern criminalistics prevention on the basis of activity of the investigator on the prevention which is carried out both in procedural, and not procedural form, and also activity of the expert revealing at production of expert researches of the circumstances promoting Commission of crime is explained.
\end{abstract}

Ключевые слова: криминалистика, криминалистическая профилактика, причины и условия преступлений, следственная профилактика, экспертная профилактика.

Key words: criminalistics, crime prevention, the causes and conditions of crimes, investigation, prevention, peer prevention.

Общеизвестно, что криминалистическая профилактика является неотъемлемой составной частью деятельности по расследованию преступления. Попытки выделить криминалистическую профилактику из следственной деятельности, а потом показать их неразрывную сущность, вызывают определенные затруднения. Следственную деятельность невозможно представить изолированно от профилактики по причине того, что, расследуя 
преступление, следователь обязан установить его причины (иначе преступление не будет раскрыто), а установив их, обязан принять меры к их устранению (в противном случае прокурор не утвердит обвинительное заключение). Отсюда следует вывод: деятельность по расследованию преступлений и деятельность по установлению его причин - едины и неделимы, и объединяют эти две составляющие именно причинно-следственные связи.

Расследование преступлений традиционно протекает по одной и той же схеме. Установив один из элементов состава преступления (на практике, в большинстве случаев, - это объективная сторона, например, произошло дорожно-транспортное происшествие (ДТП)), следователь обязан установить и оставшиеся три элемента (объект, субъект и субъективную сторону, т.е. автомобили, участвовавшие в ДТП, факт причинения тяжкого вреда здоровью потерпевшим или их гибель и данные о личности водителя, причастного к ДТП), и не просто установить «крест доказательств» (такой термин широко используется специалистами в сфере уголовного права) в виде объекта, объективной стороны, субъекта и субъективной стороны, но и «скрепить» эти элементы причинно-следственными связями. В примере о ДТП - установить, по крайней мере, располагал ли водитель технической возможностью избежать ДТП, т.е. момент времени, с которого нормальная дорожная обстановка превратилась в аварийную, интервал времени, в течение которого водитель имел возможность избежать ДТП, и момент столкновения - наезда, повлекшего либо смерть потерпевшего, либо причинение тяжкого вреда его здоровью. Доказав эти и иные обстоятельства, перечисленные в ч. 1 ст. 73 УПК РФ, следователь обязан выполнить требования ч. 2 ст. 73 УПК РФ и выявить обстоятельства, способствовавшие совершению преступления, т.е. установить те причины, совокупность которых позволяет утверждать, что преступление расследовано полно, объективно и всесторонне. В примере о ДТП -установить несоответствие скорости движения автомобиля, избранной водителем, требованиям безопасности движения, поскольку последний был, например, некачественно подготовлен в автошколе. После выявления перечисленных обстоятельств, которые в криминалистике называют причинами и условиями, способствовавшими совершению преступления, следователь обязан принять меры к их устранению, т.е. принять соответствующие меры профилактики. В нашем примере - приостановить деятельность автошколы, подготовившей неграмотного водителя и проверить её деятельность на предмет соответствия техническим и образовательным стандартам обучения водителей. Поэтому, по нашему мнению, причинно-следственные связи между расследованием и профилактикой достаточно очевидны. Расследование не может считаться завершенным без принятия мер профилактического характера. В свою очередь, меры профилактики нецелесообразно применять, если преступление расследовано однобоко, неполно и необъективно.

Повторимся: разделить процесс расследования и профилактическую деятельность невозможно. Но, как и в каждом правиле, могут быть исключения. Так, в случае, если преступление не раскрыто, то вполне естественно, что его причины не установлены, следовательно, о мерах профилактики говорить преждевременно. Правда, и в этой ситуации имеется исключение: даже если преступление не раскрыто и лицо, подлежащее уголовной ответственности, не установлено, в ряде случаев организовать профилактические мероприятия правоохранительные органы обязаны. Например, в случаях серийных убийств и изнасилований, когда преступник годами скрывается от правосудия, продолжая свою преступную деятельность, профилактической мерой является усиление контроля за теми участками местности, где наиболее часто происходят нападения на жертвы. В этих местах (парках, улицах) налаживается освещение в темное время суток, туда направляются дополнительные наряды полиции при патрулировании и т.д.

Под профилактикой (от греческого слова prophylaktikos - предохранительный) - понимается совокупность предупредительных мероприятий, направленных на сохранение и укрепление нормального состояния, порядка [Ожегов 1989]. Профилактика преступлений - не изобретение отечественных юристов. Идея профилактики прозвучала уже в трактатах Платона, где он высказался за ряд уголовно-профилактических идей и советовал 
законодателю так составлять законы, чтобы отвращать от преступления тех, которые могут сделаться преступниками из-за несовершенства законов. Профилактика преступлений исследовалась и другим виднейшим ученым древности, например, Аристотелем, который прямо писал об этом явлении, осознавая, что с преступлением не только нужно бороться, но и по возможности постараться предупредить его [Иванов, 2004].

В Русском государстве идея профилактики, пожалуй, впервые прозвучала в XXI веках, в Уставе Владимира Мономаха, который являлся составной частью сборника древнерусских правовых норм - «Русской Правды (Пространной редакции)». В дальнейшем она нашла свое отражение и развитие в Указах Петра I, Уставе о предупреждении и пресечении преступлений, вступившем в действие в 1832 году [Гиляровский, 2007] и других нормативно-правовых документах.

Научными проблемами организации профилактики преступлений в Российской Империи достаточно активно занимались видные ученые-юристы. К таковым следует отнести Б.Н. Чичерина, считавшего, что государство должно энергично заботиться о благе общества и самого себя как политического союза [Иванов,2004, с. 23-24].

В советский период развития российского государства проблема профилактики также не осталась вне поля зрения ученых-криминалистов. Идею создания теории криминалистической профилактики выдвинул в 1961 г. В.П. Колмаков. Эта идея длительное время оставалась слабо разработанной [Колмаков, 1961]. В 70-е годы XX века, судя по материалам фундаментальных трудов общепризнанного лидера отечественного криминалистического научного знания Р.С. Белкина [Колмаков, 1961, с. 129], криминалистика, как и криминология уже занимались проблемами предупреждения преступлений, но между ними не было дублирования. Предметом криминалистической профилактики являлись такие меры предупреждения преступлений, как технические и тактические. Они основывались на закономерностях возникновения доказательств и работы с ними (например, технические меры охраны определенных объектов).

В этой связи можно отметить работу криминалиста А.Г. Лекаря, в которой он предложил структуру криминалистической профилактики преступлений [Лекарь, 1972], работы В.Ф. Зудина [Зудин, 1983], многих других отечественных криминалистов.

Криминалистическая профилактика периода «перестройки» и формирования суверенной российской государственности в силу ряда причин была вынуждена базироваться на обобщении и анализе расследования уголовных дел в определенном регионе за весьма непродолжительный период времени. В этой связи в обстоятельствах колоссального роста преступности ученые-криминалисты, не прекращая исследований в области профилактической деятельности следователя, вынуждены были обратиться к криминалистической профилактике как к самостоятельному криминалистическому учению и обосновать его основные атрибуты.

С этого времени система научных знаний о криминалистической профилактике и ее месте в общей системе криминалистики постоянно пополняется новыми трудами ученых, среди которых следует отметить работы В.К. Гавло, И.И. Иванова, А.М. Кустова, В.В. Степанова, С.А. Шейфера, М.Ш. Махтаева, Н.П. Яблокова и других ученых.

В XXI веке по данной проблематике были защищены докторские диссертации М.Ш. Махтаевым «Проблемы криминалистического обеспечения предупреждения преступлений» (2001 г.), Ивановым И.И. «Криминалистическая превенция: комплексное исследование генезиса, состояния, перспектив» (2004 г.).

М.Ш. Махтаев посвятил свой труд общим положениям криминалистики и криминалистической профилактики, под которыми он рассматривал учение о закономерностях возникновения, обнаружения, собирания, исследования, оценки и использования криминалистически значимой информации об обстоятельствах, способствующих совершению и сокрытию преступлений и основанных на познании этих закономерностей специальных средствах, приемах и методах криминалистики, направленных на устранение указанных обстоятельств, а также на предупреждение готовящихся и пресечение начавшихся пре- 
ступлений [Махтаев, 2001]. Вероятно, М.Ш. Махтаев прав, обратив внимание на готовящиеся преступления. Однако, по нашему мнению, криминалистическая профилактика гораздо шире и глубже, и начинаться должна даже не с момента начала вынашивания каким-либо субъектом замысла на совершение преступления, а гораздо раньше, например, с момента принятия явно непродуманного законодательного акта, открывающего возможности для нецелевого использования государственного бюджета, других преступлений.

Внимание И.И. Иванова в значительной степени уделено типичным элементам профилактики на различных этапах расследования преступлений. Применительно к первоначальному этапу расследования - это следственные действия по сбору информации профилактического содержания, предотвращению замышляемых и подготавливаемых преступлений, своевременному обнаружению, быстрому раскрытию совершенных преступлений, пресечению конкретной преступной деятельности, выявлению обстоятельств, способствовавших совершению и сокрытию преступлений и признаков противодействия расследованию.

Для последующего этапа расследования, по мнению Иванова, характерны следственные действия, направленные на полное раскрытие преступлений, ликвидацию опасных последствий конкретной преступной деятельности, преодоление противодействия расследованию [Иванов, 2004].

Интересно, что точки зрения двух ведущих профессоров, Р.С. Белкина и Н.П. Яблокова, о природе криминалистической профилактики практически совпали. Так, профессор Н.П. Яблоков на одной из конференций, состоявшихся в 1997 г., высказал мнение о том, что криминалистическая профилактика содержит два направления: первое - в экспертной профилактике, второе - в изучении профилактических основ следственной практики. По его мнению, основой для экспертно-криминалистической профилактики являются экспертная практика и данные криминалистической техники [ЯБЛОКОВ, 1997, с. 110111]. Профессор Р.С. Белкин в работе 1999 г. также посчитал, что криминалистическая профилактика должна развиваться по двум направлениям [Белкин, 1999].

Представляет интерес точка зрения А.А. Баракшина, который предложил изучать проблемы криминалистической профилактики применительно к конкретным ситуациям, возникающим в деятельности следователя. По его мнению, к особенностям, формирующим такого рода ситуации по расследуемым делам, можно отнести следующие факторы: 1) объем и качество криминалистически значимой информации об обстоятельствах, способствовавших совершению преступления; 2) характер источников криминалистически значимой и иной информации о таких обстоятельствах; 3) особенности объекта предупредительного воздействия; 4) практическая целесообразность проведения соответствующих предупредительных мероприятий в анализируемый момент расследования; 4) наличие у следователя возможности четко определить характер требующегося предупредительного воздействия криминалистическими средствами на выявленный объект в данный момент в реальном для следователя объёме; 5) возможность оказания предупредительного воздействия средствами, приёмами и методами криминалистики на конкретный объект в данной ситуации; 6) отсутствие мешающих воздействию каких-либо барьеров (организационных, правовых, психологических и иных); 7) обеспеченность возможных предупредительных мероприятий реальным временем [Баракшин, 2008].

Свою точку зрения по поводу криминалистической профилактики высказали и представители саратовской школы криминалистов И.П. Можаева и В.В. Степанов [Можаева, 2007], а также специалист из Санкт-Петербурга В.В. Вандышев [1982].

Творчески развивая мысли криминалистов о профилактике преступлений, в 2011 г. Ю.Н. Аксёнова-Сорохтей в Воронежском государственном университете успешно защитила кандидатскую диссертацию «Частное криминалистическое учение о профилактике преступлений несовершеннолетних», привнеся в криминалистическую профилактику несколько достойных внимания авторских позиций, одной из которой явилось её актуальное 
предложение по созданию отдельного криминалистического учения о профилактике преступлений несовершеннолетних [Аксенова-Сорохтей, 2011].

Уже отмечалось, что сфера криминалистической профилактики преступлений существенно отличается от криминологической профилактики. По справедливому замечанию Р.С. Белкина, именно специальный характер средств и методов криминалистического предупреждения преступлений отграничивает их от средств и методов профилактики преступлений, составляющих предмет иных юридических наук [Белкин, 2001]. Действительно, проблемами криминалистической профилактики занимаются многие государственные и общественные структуры, но лишь следователь обладает тем комплексом технических, информационных, вербальных, моральных и этических средств воздействия на окружающих его лиц, чтобы намеченные им мероприятия по профилактике могли начать реализовываться немедленно. Не менее важно, что именно он, следователь, первым получает данные о первопричинах противоправного поведения правонарушителя, используя для этого различные источники информации - от вербальных до компьютерных.

Так, привлекая к участию в допросе несовершеннолетнего подозреваемого его родителей, педагогов и психологов, следователь одновременно, фактически не отрываясь от технологии и тактики допроса, может установить момент зарождения у подростка желания заняться криминальной деятельностью, высветить ряд негативных моментов, изобличающих лиц, окружающих подростка, в создании условий, приведших его в кабинет следователя. Другими словами, следователь может установить причины возникновения криминальной направленности подростка. Например, допрашивая подростка о проблемах в семье, следователь выясняет, что в ней создан культ силы, денег и единовластия, который отразился на формировании юного правонарушителя. А учитывая, что на допросе присутствуют родители подростка, следователь, даже не вынося предусмотренного ст. 158 УПК РФ представления об устранении причин и условий, способствовавших совершению преступления, обязан предупредить этих родителей об изменении взаимоотношений в семье, чтобы на скамье подсудимых не оказался следующий их «отпрыск». Допрашивая об условиях учебы и установив, что в классе сформировался негативный настрой к отличникам, приведший к изоляции подростка, и именно этот факт послужил началом формирования криминальных интересов молодого человека, следователь обязан здесь же, в своем кабинете, провести профилактическую беседу с учителем и потребовать принять меры, исключающие возвеличивание двоечников над примерными ребятами и т.д. Насколько можно судить по судебной практике, нередко уже к моменту судебного разбирательства руководители школ рапортуют суду о полном изменении отношения детей к обучению, т.е. беседа следователя была правильно понята и имела успех. Это - только один из многих примеров, когда следователь, выявив момент и причины начала формирования криминальных наклонностей у подростка, имеет право и обязан в полной мере пользоваться своими полномочиями с той целью, чтобы остальные подростки из семьи, школы и двора, не совершали аналогичных преступлений.

Помимо совершения профилактически направленных действий в ходе допроса, следователь имеет право и обязан употребить свои полномочия и авторитет для организации профилактики преступлений при проведении фактически любого следственного или иного процессуального действия. Это может касаться и очной ставки, и проверки показаний на месте, и проведения следственного эксперимента, и при избрании меры пресечения и пр. Выбор профилактирующих действий бесконечен. Он зависит от опыта, желания и времени следователя, а также от помощи со стороны руководителя следственного отдела. Как пример удачной профилактики можно привести эпизод из следственной практики, когда девочки из одного класса в туалете школы «опустили» свою одноклассницу за то, что она была, по их мнению, слишком шикарно одета. Они избили её, вырвали из её ушей золотые серёжки. При обсуждении данного деяния в классе (чему очень резко препятствовала директор школы), следователь объяснил всем старшеклассникам, что наказание за данные действия - не пятнадцать суток, как уже решили «юридически грамотные» под- 
ростки и их родители, а реальный срок в местах лишения свободы. После такого мероприятия в данной школе на протяжении, по крайней мере, следующих 10 лет не было ни одного аналогичного происшествия, хотя суд ограничился условным наказанием.

Подводя итоги вышеизложенному, считаем необходимым обратить внимание, что «бум» развития научных основ криминалистической профилактики произошел в результате фактического слома эффективно действовавшей в течение трех десятилетий системы взаимного дополнения криминологической и криминалистической профилактики, которая имела место в конце 80-х - начале 90-х годов, что было связано с отсутствием достоверной информации о состоянии преступности, поскольку она несколько лет скрывалась от ученыхкриминологов, отсутствием криминологических анализов и прогнозов (по В.В. Лунееву).

Основоположниками обновленной теории криминалистической профилактики в 1997 и 1999 годах явились профессора Р.С. Белкин, Н.П. Яблоков М.Ш. Махтаев, практически одновременно заявившие о двухвекторном развитии основ криминалистической профилактики. Первый вектор: деятельность следователя по предупреждению преступлений, осуществляемая как в процессуальной, так и не процессуальной форме. Второй вектор: деятельность эксперта, выявляющего при производстве экспертных исследований обстоятельств, способствовавших (могущих способствовать) совершению преступления.

Криминалистическая профилактика лишь тогда эффективна, когда в её основе лежат бесспорно установленные данные о первопричинах начала развития либо преступной деятельности, либо формирование криминальных черт личности конкретного субъекта, т.е. причины и условия, способствовавшие совершению преступления.

\section{Список литературы}

1. Аксенова-Сорохтей Ю.Н. 2011. Частное криминалистическое учение о профилактике преступлений несовершеннолетних: Автореферат дис. ... канд. юрид. наук. Воронеж. 23 с.

2. Баракшин А.А. 2008. Проблемы криминалистического обеспечения расследования преступлений военнослужащих. Вестник криминалистики. М., СПАРК, 2 (26): 65 с.

3. Белкин Р.С.2001. Курс криминалистики. М., ЮНИТИ-ДАНА: 69 с.

4. Белкин Р.С. 1999. Криминалистика: учебный словарь-справочник. М., Юристъ: 89 с.

5. Вандышев В.В. 1982. Криминалистическая профилактика в системе криминалистики. Правоведение, 12: 212 с.

6. Гиляровский В.А. 2007. Трущобные люди. М., Эксмо: 89 с.

7. Зудин В.Ф. 1983. Социальная профилактика. Криминологические и криминалистические проблемы. Издательство Саратовского университета: 109 с.

8. Иванов И.И. 2004. Криминалистическая превенция (комплексное исследование генезиса, состояния, перспектив): Дис. ...докт. юрид. наук. СПб., 330 с.

9. Колмаков В.П. 1961. Некоторые вопросы криминалистической профилактики преступлений. Советское государство и право, 12: 129 с.

10. Лекарь А.Г. 1972. Профилактика преступлений. М., Юридическая литература: 3-4 с.

11. Махтаев М.Ш. 2001. Основы теории криминалистического предупреждения преступлений: монография. М., Раритет: 96 с.

12. Можаева И.П., Степанов В.В. 2007. Организация расследования преступлений. Вестник криминалистики, 1 (21): 43 с.

13. Ожегов С.И. Словарь русского языка. 1989. Под ред. чл.-корр. АН СССР Н.Ю. Шведовой. М., Рус. яз. С.145.

14. Яблоков Н.П. 1997. Криминалистика и предупреждение преступлений. Материалы Всероссийской научно-практической конференции по проблеме профилактики правонарушений. M., C. 64.

\section{References}

1. Aksenova-Sorohtej YU.N. 2011. Chastnoe kriminalisticheskoe uchenie o profilaktikeprestuplenij nesovershennoletnih [Private criminalistic doctrine about the prevention of crimes of minors]: Avtoreferat dis. ... kand. yurid. nauk. Voronezh. 23 p. 
2. Barakshin A.A. 2008. Problemy kriminalisticheskogo obespecheniya rassledovaniyaprestuplenij voennosluzhashchih [Problems as to criminal maintenance of investigation of crimes military personnel]. Vestnikkriminalistiki [Journal of criminology]. M., SPARK, 2 (26): 65 p.

3. Belkin R.S. 2001. Kurskriminalistiki [Course criminology]. M., YUNITI-DANA: 69 p.

4. Belkin R.S. 1999. Kriminalistika: uchebnyjslovar'-spravochnik [Criminalistics: educational dictionary-reference book]. M., YUrist": 89 p.

5. Vandyshev V.V. 1982. Kriminalisticheskaya profilaktika v sisteme kriminalistiki [Forensic prevention in the system of criminology]. Pravovedenie [Jurisprudence], 12: $212 \mathrm{p}$.

6. Gilyarovskij V.A. 2007. Trushchobnyelyudi [Slum people]. M., Eksmo: 89 p.

7. Zudin V.F. 1983. Social'nayaprofilaktika [Social preventive maintenance]. Kriminologicheskieikriminalisticheskie problem [Criminological and criminological problems]. Izdatel'stvo Saratovskogo universiteta: $109 \mathrm{p}$.

8. Ivanov I.I. 2004. Kriminalisticheskayaprevenciya (kompleksnoeissledovaniegenezisa, sostoyaniya, perspektiv) [Forensic prevention (comprehensive study of Genesis, condition, prospects)]: Dis. ...dokt. yurid. nauk. SPb., 330 p.

9. Kolmakov V.P. 1961. Nekotorye voprosy kriminalisticheskoj profilaktiki prestuplenij [Some questions of criminalistic crime prevention]. Sovetskoe gosudarstvo I parvo [Soviet state and law], 12: $129 \mathrm{p}$. tura: 3-4 p.

10. Lekar' A.G. 1972. Profilaktikaprestuplenij [Crime prevention]. M., YUridicheskayalitera-

11. Mahtaev M.SH. 2001. Osnovyteoriikriminalisticheskogopreduprezhdeniyaprestuplenij [Fundamentals of the theory of criminalistic prevention of crimes]: Monografiya. M., Raritet: $96 \mathrm{p}$.

12. Mozhaeva I.P., Stepanov V.V. 2007. Organizaciyarassledovaniyaprestuplenij [the Organization of crime investigation]. Vestnikkriminalistiki [Journal of criminology], 1 (21): 43 p.

13. Ozhegov S.I. Slovar' russkogoyazyka [Dictionary of Russian language]. 1989. Pod red. chl.korr. AN SSSR N.YU. SHvedovoj. M., Rus. yaz. P. 145.

14. Yablokov N.P. 1997. Kriminalistika i preduprezhdenie prestuplenij [Criminalistics and crime prevention]. Materialy Vserossijskoj nauchno-prakticheskoj konferencii po problem profilaktiki pravonarushenij [Proceedings of the all-Russian scientific and practical conference on the problem of crime prevention]. M., P. 64.

\section{Ссылка для цитирования статьи Reference to article}

Игнатьев М.Е. 2019. Криминалистическая задача расследования - установление причин и условий, способствующих совершению преступления. Научные ведомости Белгородского государственного университета. Серия: Философия. Социология. Право. 44 (3): 467-473. DOI 10.18413/2075-4566-2019-44-3-467-473

Ignatiev M.E. 2019. Forensic investigation into the causes of and conditions conducive to committing a crime. Belgorod State University Scientific Bulletin. Philosophy. Sociology. Law series. 44 (3): 467-473 (in Russian). DOI 10.18413/2075-4566-2019-44-3-467-473 